\title{
Cognitive effects of high-frequency repetitive transcranial magnetic stimulation: a systematic review
}

\author{
Birgit Guse $\cdot$ Peter Falkai $\cdot$ Thomas Wobrock
}

Received: 29 April 2009/ Accepted: 7 October 2009/Published online: 27 October 2009

(C) Springer-Verlag 2009

\begin{abstract}
Transcranial magnetic stimulation (TMS) was introduced as a non-invasive tool for the investigation of the motor cortex. The repetitive application (rTMS), causing longer lasting effects, was used to study the influence on a variety of cerebral functions. High-frequency $(>1 \mathrm{~Hz})$ rTMS is known to depolarize neurons under the stimulating coil and to indirectly affect areas being connected and related to emotion and behavior. Researchers found selective cognitive improvement after high-frequency (HF) stimulation specifically over the left dorsolateral prefrontal cortex (DLPFC). This article provides a systematic review of HF-rTMS studies (19992009) stimulating over the prefrontal cortex of patients suffering from psychiatric/neurological diseases or healthy volunteers, where the effects on cognitive functions were measured. The cognitive effect was analyzed with regard to the impact of clinical status (patients/healthy volunteers) and stimulation type (verum/sham). RTMS at 10, 15 or $20 \mathrm{~Hz}$, applied over the left DLPFC, within a range of 1015 successive sessions and an individual motor threshold of $80-110 \%$, is most likely to cause significant cognitive improvement. In comparison, patients tend to reach a greater improvement than healthy participants. Limitations concern the absence of healthy groups in clinical studies and partly the absence of sham groups. Thus, future investigations are needed to assess cognitive rTMS effects in different psychiatric disorders versus healthy subjects using an extended standardized neuropsychological test battery. Since the pathophysiological and neurobiological
\end{abstract}

B. Guse $(\square)$ · P. Falkai · T. Wobrock

Department of Psychiatry and Psychotherapy,

Georg-August-University Göttingen,

Von-Siebold-Straße 5, 37075 Gottingen, Germany

e-mail: bguse@gwdg.de basis of cognitive improvement with rTMS remains unclear, additional studies including genetics, experimental neurophysiology and functional brain imaging are necessary to explore stimulation-related functional changes in the brain.

Keywords Transcranial magnetic stimulation . High-frequency rTMS · Prefrontal cortex · Cognition

$\begin{array}{ll}\text { Abbreviations } & \\ \text { DLFPC } & \text { Dorsolateral prefrontal cortex } \\ \text { TMS } & \text { Transcranial magnetic stimulation } \\ \text { rTMS } & \begin{array}{l}\text { Repetitive transcranial magnetic } \\ \text { stimulation }\end{array} \\ \text { D } & \text { Depression } \\ \text { BD } & \text { Bipolar disorder } \\ \text { ExDys } & \text { Executive dysfunction } \\ \text { H } & \text { Healthy } \\ \text { MC } & \text { Memory complaints } \\ \text { PD }+ \text { D } & \text { Parkinson's Disease }+ \text { Depression } \\ \text { Pstr D } & \text { Poststroke depression } \\ \text { SZ } & \text { Schizophrenia } \\ \text { PC } & \text { Parietal cortex } \\ \text { AMI } & \text { Autobiographical Memory Interview } \\ \text { (R)/(H)AVLT } & \text { (Rey)/(Hopkins) Auditory Verbal } \\ & \text { Learning Test } \\ \text { BSRT } & \text { Buschke Selective Reminding Test } \\ \text { BVRT } & \text { Benton's Visual Retention Test } \\ \text { COWAT } & \text { Controlled Oral Word Association } \\ & \text { Test } \\ \text { CPM } & \text { Colored Progressive Matrices } \\ \text { CPT } & \text { Continuous Performance Test } \\ \text { CVLT } & \text { California Verbal Learning Test } \\ \text { DSST } & \text { Digit Symbol Substitution Test } \\ & \end{array}$




$\begin{array}{ll}\text { EPAT } & \text { Expanded Paired Associate Test } \\ \text { GOAT } & \text { Galveston Orientation and Amnesia } \\ & \text { Test } \\ \text { HVOT } & \text { Hooper Visual Organization Test } \\ \text { JLO } & \text { Judgement of line orientation } \\ \text { LPS } & \text { Lernprüfsystem } \\ \text { MMST } & \text { Mini Mental Status Test } \\ \text { MPT } & \text { Memory for Past Test } \\ \text { MVG } & \text { Münchner Verbaler Gedächtnistest } \\ \text { NART } & \text { New Adult Reading Test } \\ \text { NCT } & \text { Number Connection Test } \\ \text { PAG } & \text { 'Traffic Lights Test' } \\ \text { SILS } & \text { Shipley Institute of Living Scale } \\ \text { SSMQ } & \text { Squire Subjective Memory } \\ & \text { Questionnaire } \\ \text { Stroop } & \text { Stroop Interference Test } \\ \text { TMT (A/B) } & \text { Trail Making Test Version A/B } \\ \text { VFT } & \text { (Letter) Verbal Fluency Test } \\ \text { VPAL } & \text { Visual paired associates learning } \\ \text { WAIS(-R) } & \text { Wechsler intelligence scale } \\ & \text { (Revised) } \\ \text { WMS(-R)/WMSIII } & \text { Wechsler memory scale } \\ & \text { (Revised)/3 version } \\ \text { ExFunction } & \text { Executive function } \\ \text { WM } & \text { Working memory }\end{array}$

\section{Introduction}

Since transcranial magnetic stimulation (TMS) was introduced by Barker et al. (1985) as a non-invasive tool for the investigation of the motor cortex, repetitive applications of this technique (rTMS) were used to study the influence on a variety of cerebral functions. TMS is based on an electromagnetic coil applied to the scalp producing an intense, localized magnetic field which either excites or inhibits a focal cortical area. Repetitive TMS uses alternating magnetic fields to induce electric currents in the cortical tissue (Burt et al. 2002). Low-frequency ( $\leq 1 \mathrm{~Hz})$ rTMS is likely to cause inhibition of neuronal firing in a localized area, whereas high-frequency $(>1 \mathrm{~Hz})$ rTMS inversely leads to neuronal depolarization under the stimulating coil (Haraldsson et al. 2004). The effects induced are not limited to the targeted cortical region, changes can also occur at distant interconnected sites in the brain. The efficacy of rTMS treatment on affective disorders may not be restricted to the activating effects under the stimulated prefrontal area, but also due to the secondary affection of subcortical areas being functionally related to emotion and behavior (Burt et al. 2002; Post and Keck 2001; Ben-Shachar et al. 1997; Conca et al. 1996; Cordes et al. 2005; Gershon et al. 2003).
Recently, rTMS has also been employed to explore the treatment options for schizophrenia patients due to the growing observation of non-responders to antipsychotic agents (Hajak et al. 2004; Hoffmann et al. 2005; Jandl et al. 2004). According to different stimulation protocols evidence is accumulating about the improving effect of rTMS on acoustic hallucinations and negative symptoms in schizophrenia (Hoffmann et al. 2005; Jandl et al. 2004, 2005; Poulet et al. 2005). The well-established electroconvulsive therapy (ECT) exhibits proven antidepressant effects, but it is also known to produce temporary adverse cognitive effects (e.g. memory deficits) (Squire 1982; Sackeim et al. 1986; Weiner et al. 1986). Behind this background many rTMS studies were used to assess cognitive functions additionally to control for cognitive disturbances (Triggs et al. 1999; Padberg et al. 1999; Schulze-Rauschenbach et al. 2005). In contrast to the original assumption of cognitive deterioration selective improvements in patients after high-frequency rTMS $(10 \mathrm{~Hz}$ or $20 \mathrm{~Hz}$ ) over the left prefrontal sites were observed. This finding leads to further investigations measuring rTMS-related cognitive changes in patients or healthy volunteers. However, the influence of the various stimulation parameters (e.g. frequency, intensity, train duration and duration of whole stimulation period) on cognition and the extent of changes in cognitive performance remained unclear.

The aim of the presented work is to provide a systematic overview of high-frequency rTMS (HF-rTMS) studies assessing neurocognition for better understanding the potential of rTMS to induce long-term effects on cognition. In addition, the efficacy of HF-rTMS on distinct cognitive domains will be outlined. The aim of the review is not to summarize the effects of studies with rTMS to study cognitive function by creating a 'functional lesion'. Most of these studies use rTMS as "online rTMS" to interfere temporarily with neuronal functioning in order to gain information about the functional contribution of the stimulated area during performing a particular task (Sack and Linden 2003). We primarily included studies in our systematic review which investigate the after effects of HF-rTMS, as "offline rTMS", at first glance independent of the amount of rTMS sessions, but we were interested in studies investigating cognitive effects using more than a single rTMS session.

\section{Method}

We performed a systematic literature search in the following databases: PubMed (1999-2009) and MEDLINE (1999-2009). A great range of search terms were used: "repetitive TMS" or "rTMS" and "cognition" or "cognitive dysfunction", "cognitive impairment", "executive function", 
"information processing", "processing speed", "reaction time", "learning", "memory", "set shifting", "flexibility", "Wisconsin Card Sorting Test", "response inhibition", "response suppression", "attention" or "verbal fluency".

In the literature search, we identified 80 hits that appeared to be suitable upon careful review of their titles and abstracts. Of these 80 publications there were 5 studies dealing with effects of other stimulation techniques (e.g. transcranial direct current stimulation, tDCS) and excluded, 45 studies using low-frequency repetitive transcranial magnetic stimulation (LF-rTMS) and 30 studies with HF-rTMS. We then read through the full text of the 30 papers summarizing the results of HF-rTMS studies, evaluated and included the data in our review. Review papers and the references in the appraised studies were therefore used for a renewed search for further relevant literature. This did not lead to further inclusions in our systematic review. Studies were considered only if they had been published in English or German language and described adequately the sample, the application procedure and the trial design. We only included offline-paradigms.

Although we focused on high-frequency stimulation, we initially took into account low-frequency studies $(n=45)$ to better evaluate frequency-dependent cognitive changes. A great amount of them were excluded $(n=41)$ subsequently because (1) they focus on disruptive effect measures (e.g. by inducing 'virtual lesions' in onlineparadigms), or (2) they focus on other topics not describing cognitive testing or the stimulation procedure adequately (e.g. methodology and safety studies, some case reports or meta-analyses).

In conclusion, all studies fulfilling our predefined selection criteria were taken into account and evaluated according to their relative cognitive outcome.

\section{Results}

Description of the studies

The identified publications consist of 6 open studies and 24 controlled studies including within-subject-, shamcontrolled- or crossover designs. The studies comprise 22 clinical trials with major depression, that contain one comparative trial with healthy subjects being matched to the patient population in age, gender and level of education. One of these studies includes patients with Parkinson Disease and major or minor depression, one includes only elders (between 40 and 90 years) with major depression and another one contains post-stroke depressives. Further, three clinical studies integrate schizophrenic patients, one study contains patients with cerebrovascular disease and mild executive dysfunction, another trial investigates elder people with memory complaints. Overall, three studies involve only healthy volunteers. The majority of the included psychiatric patients were diagnosed and classified on operational criterion-based systems for depression (Diagnostic and Statistical Manual of Mental Disorder IV), a smaller part met criteria by formal diagnostic interview on the Structured Clinical Interview for DSM-IV Axis I Disorders (SCID). The others were rated by means of particular neurological/psychological tests and imaging data. The characteristics of the included subjects, stimulation protocols, cognitive ratings and outcomes of all identified studies assessing the efficacy of rTMS on cognition are outlined in Table 1 .

The cognitive assessments used in the listed studies differ from study to study, no standardized cognitive test battery has been used consistently. Therefore, various cognitive domains are involved to perform the selected cognitive testing and the results of the studies are not completely comparable.

\section{Cognitive effects of high-frequency rTMS} over the prefrontal cortex

The differential cognitive effect of excitatory rTMS is outlined in Table 2. Cognitive domains are subdivided and the reported ameliorations, deteriorations or missing cognitive rTMS effects are linked to the corresponding studies. The studies were grouped by significant improvement or deterioration in the columns, studies showing trends toward improvements or deterioration were summarized among in the column "no effects (n. s.)". One study (Vanderhasselt et al. 2009) was not included in the table because cognitive effects were too specific to be adequately categorized.

In the literature search about 19 studies were found assessing changes of attention after stimulation, showing inconsistent results. Among these studies there are 13 clinical trials and 3 non-clinical trials. In alertness/simple reaction time no significant effect was found when measured separately (Padberg et al. 1999; Loo 2001; Shajahan et al. 2002). With the Go-/No Go- or the Stroop-Paradigm some authors could detect improvements in selective attention (Hausmann et al. 2004; Martis et al. 2003; Rektorova et al. 2005), some others did not find statistically relevant effects (Avery et al. 2006; Boggio et al. 2005; Huang et al. 2004; Jorge et al. 2004; Moser et al. 2002; Mosimann et al. 2004; Speer et al. 2001; Vanderhasselt et al. 2006; Wagner et al. 2006). One of these studies reports on deteriorations in visual reaction time in the subtest divided attention of the "Testbatterie zur Aufmerksamkeitsprüfung (TAP, Zimmermann and Fimm 1997)" (Wagner et al. 2006). In sustained attention/concentration two studies give implications for improvements (Höppner et al. 2003; Rektorova et al. 2005), others failed 


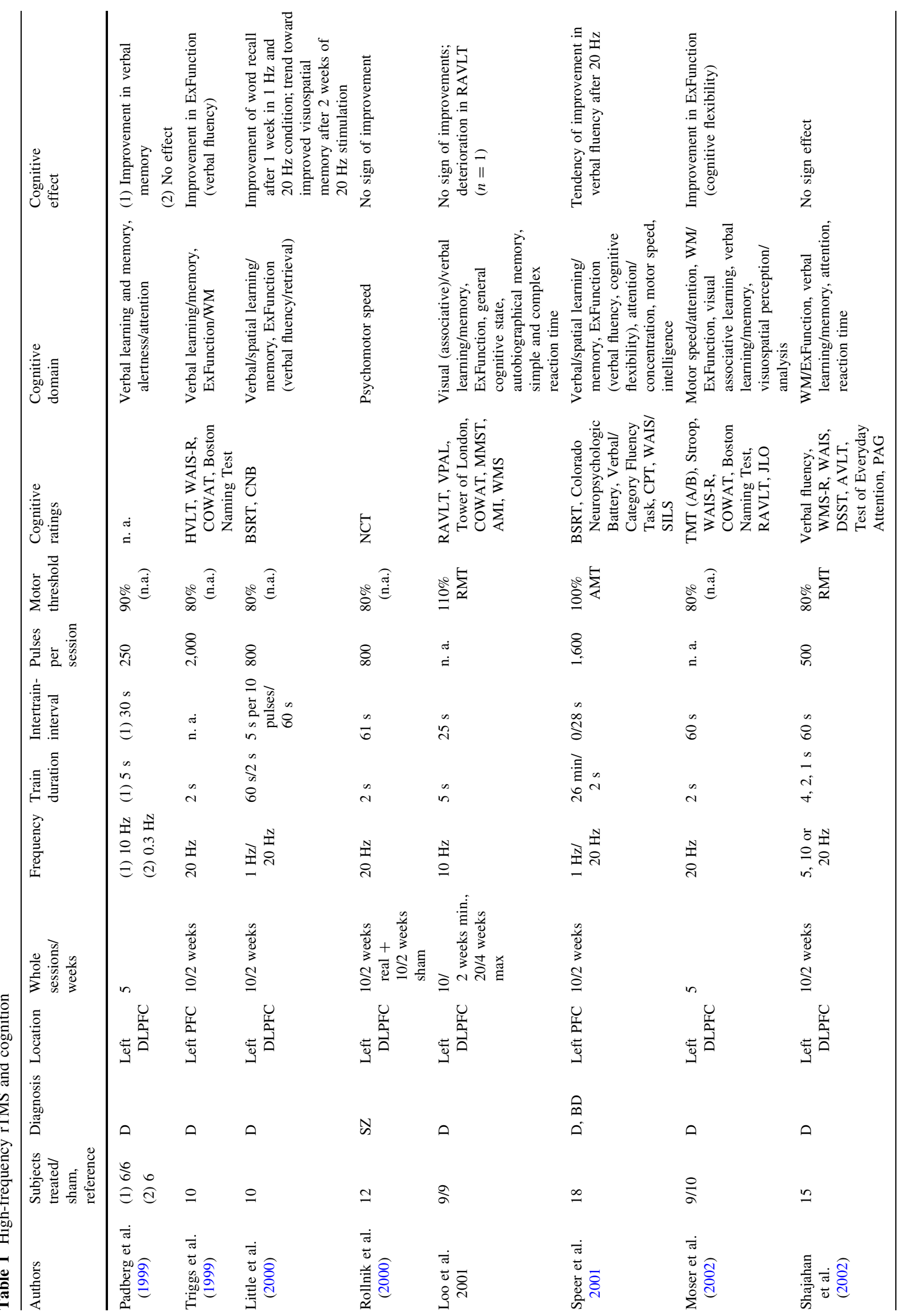




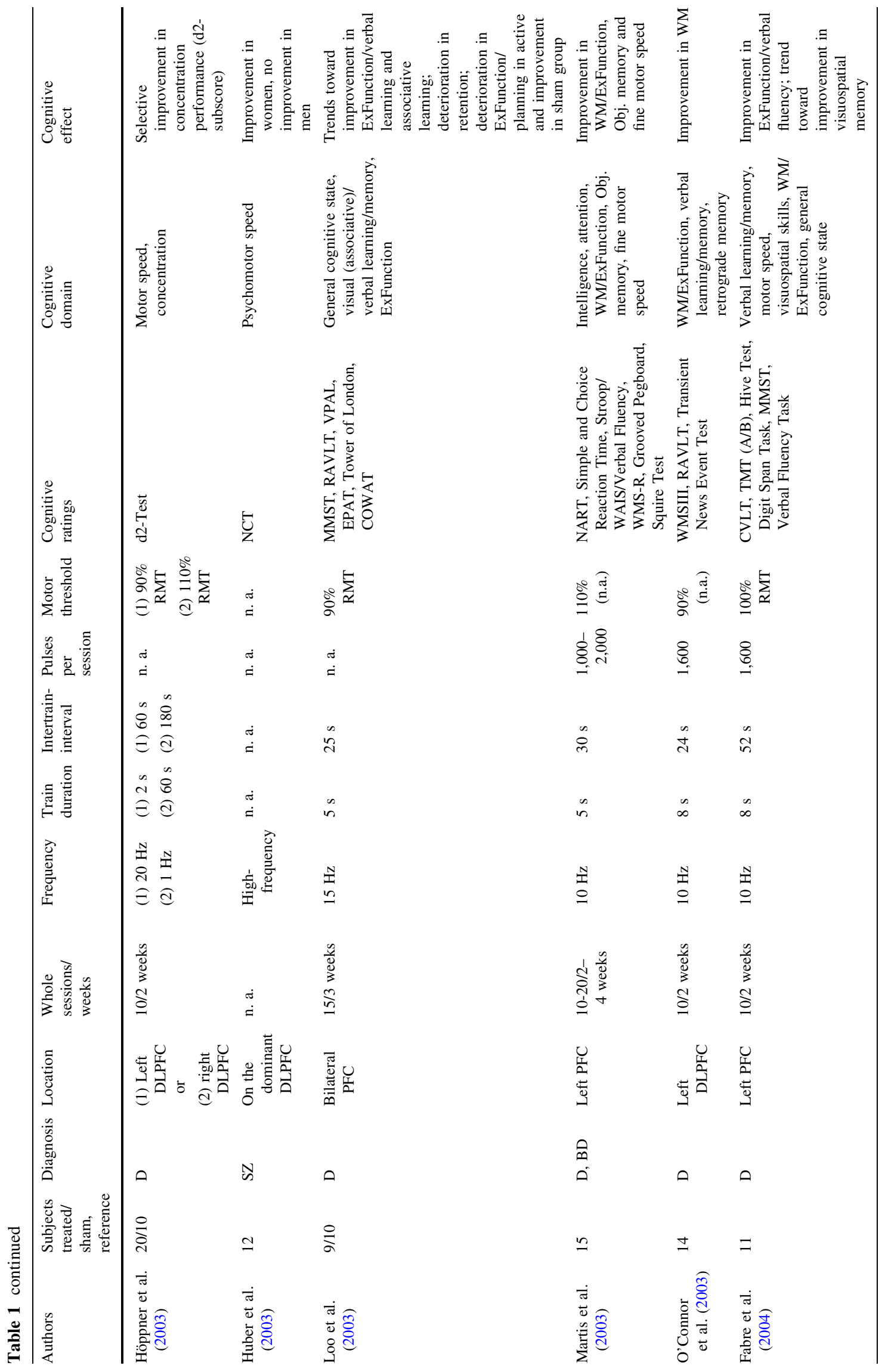




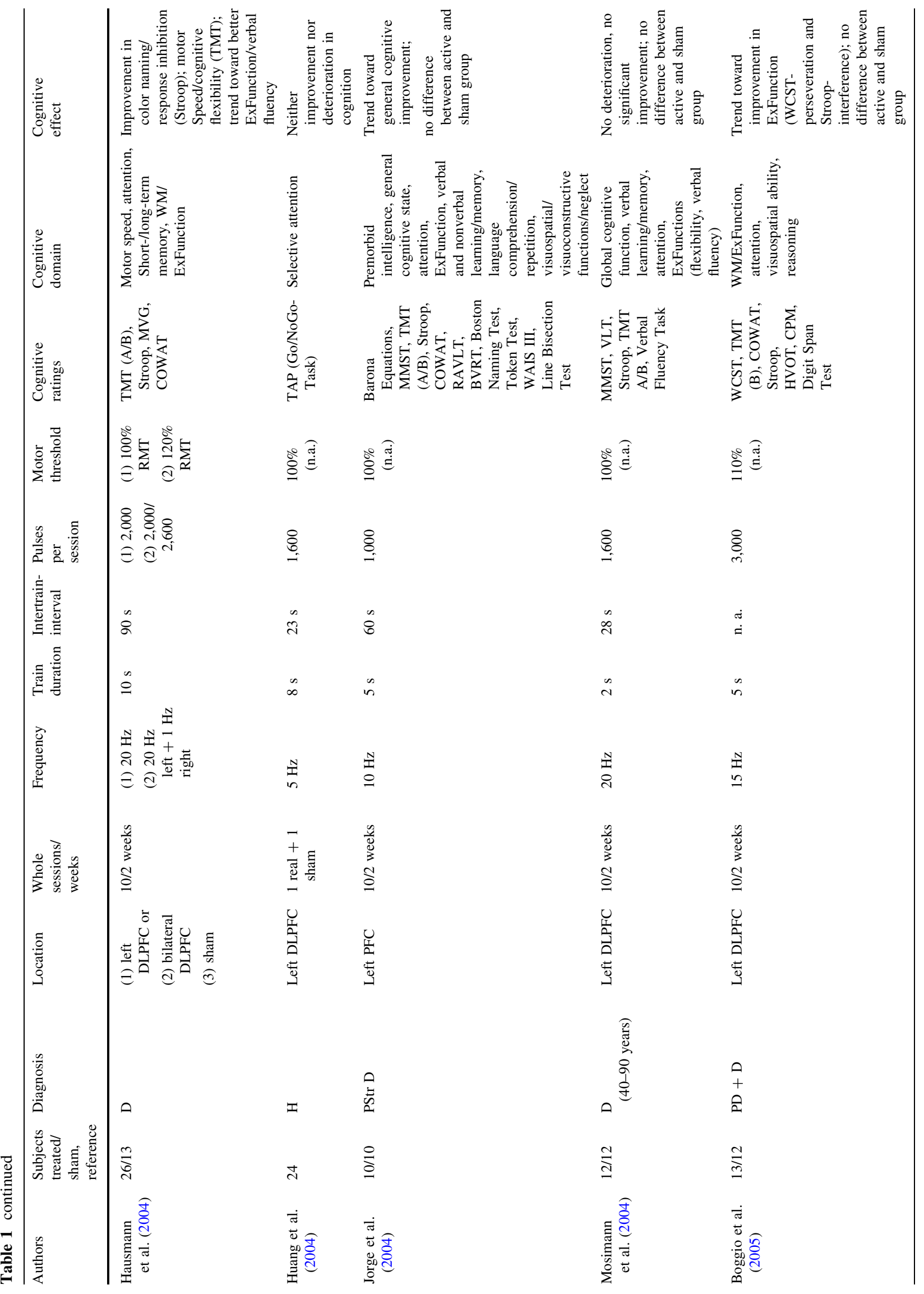


Cognitive effects of prefrontal rIMS

111

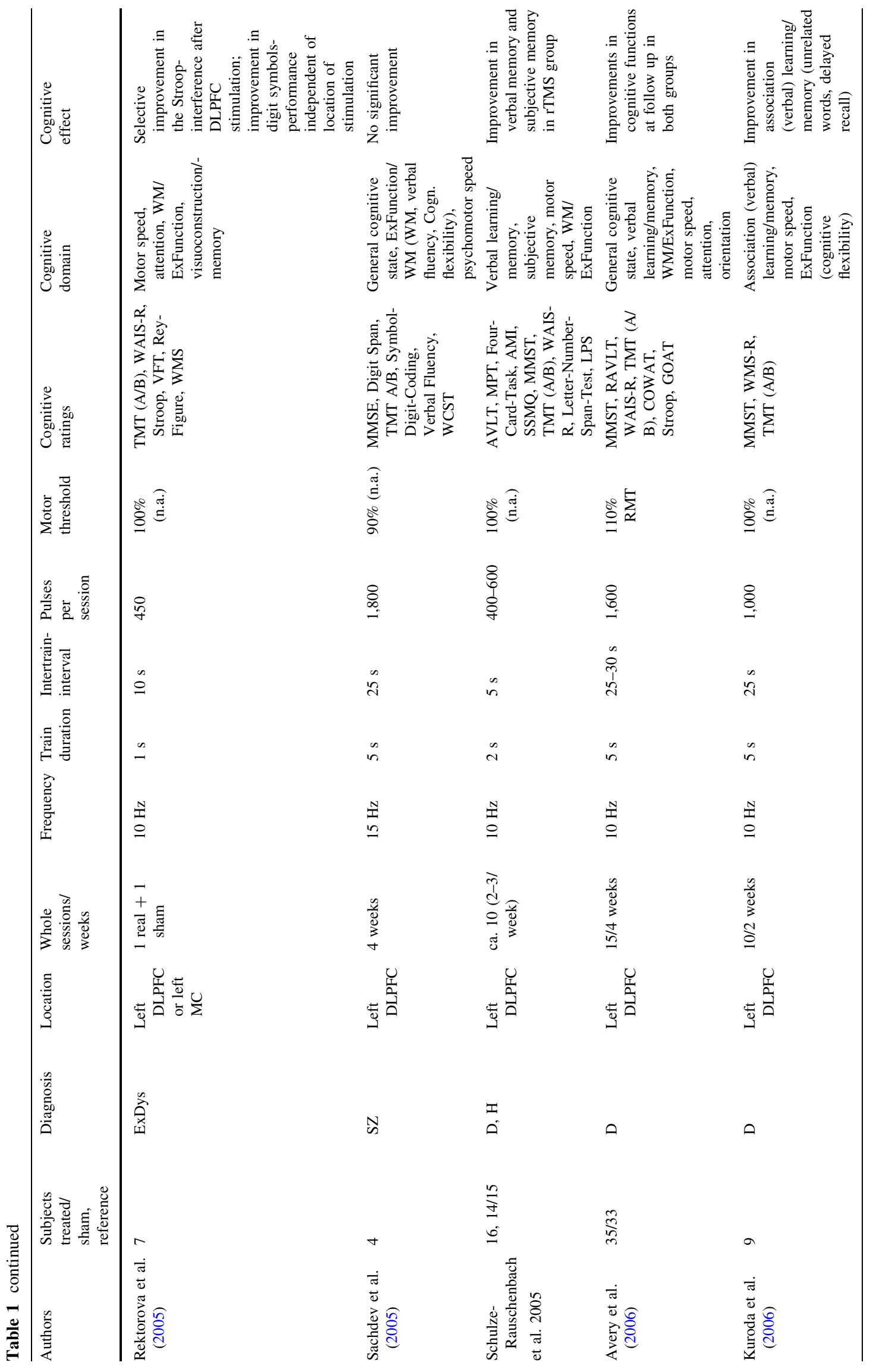

刑 Springer 


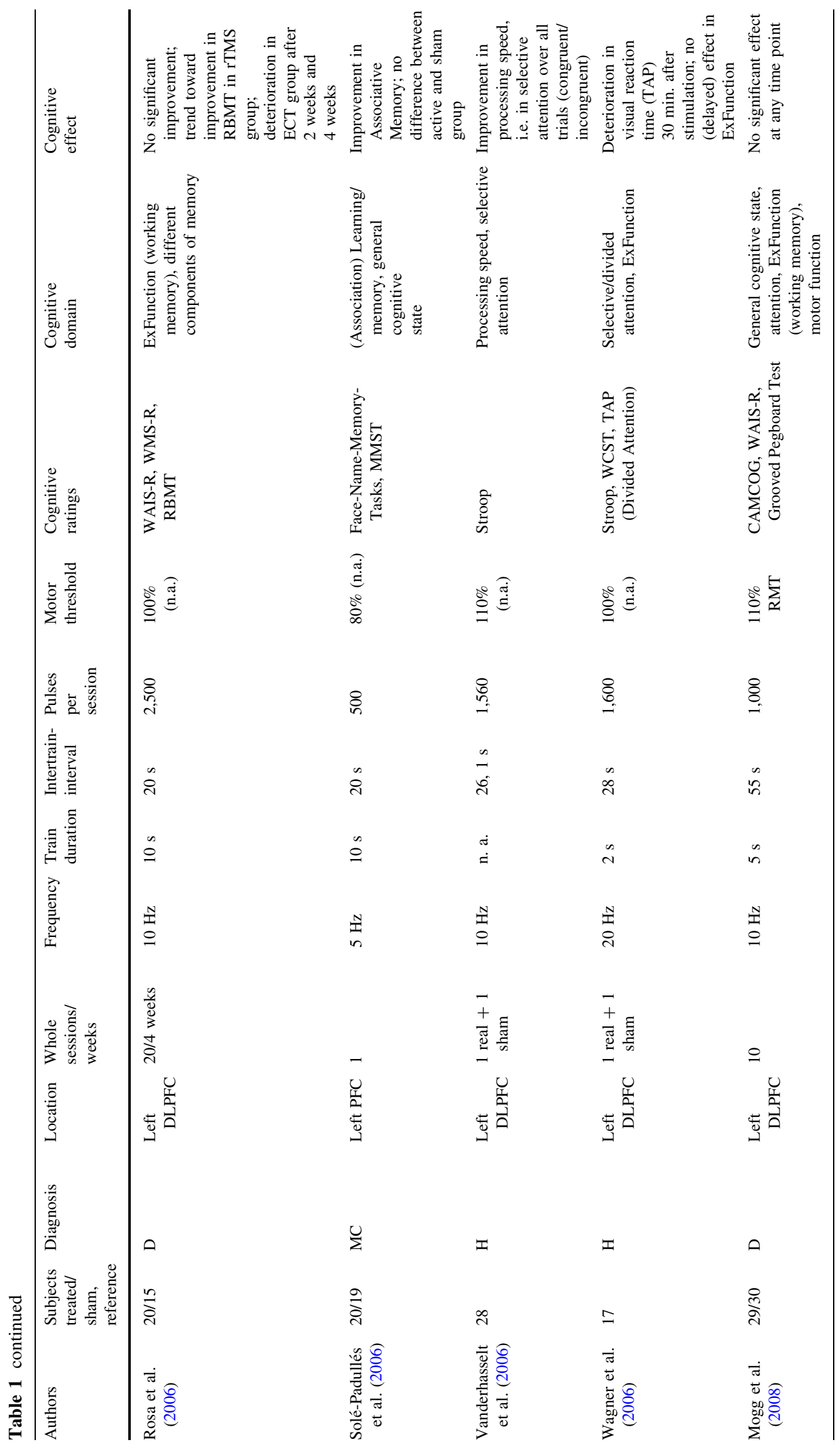




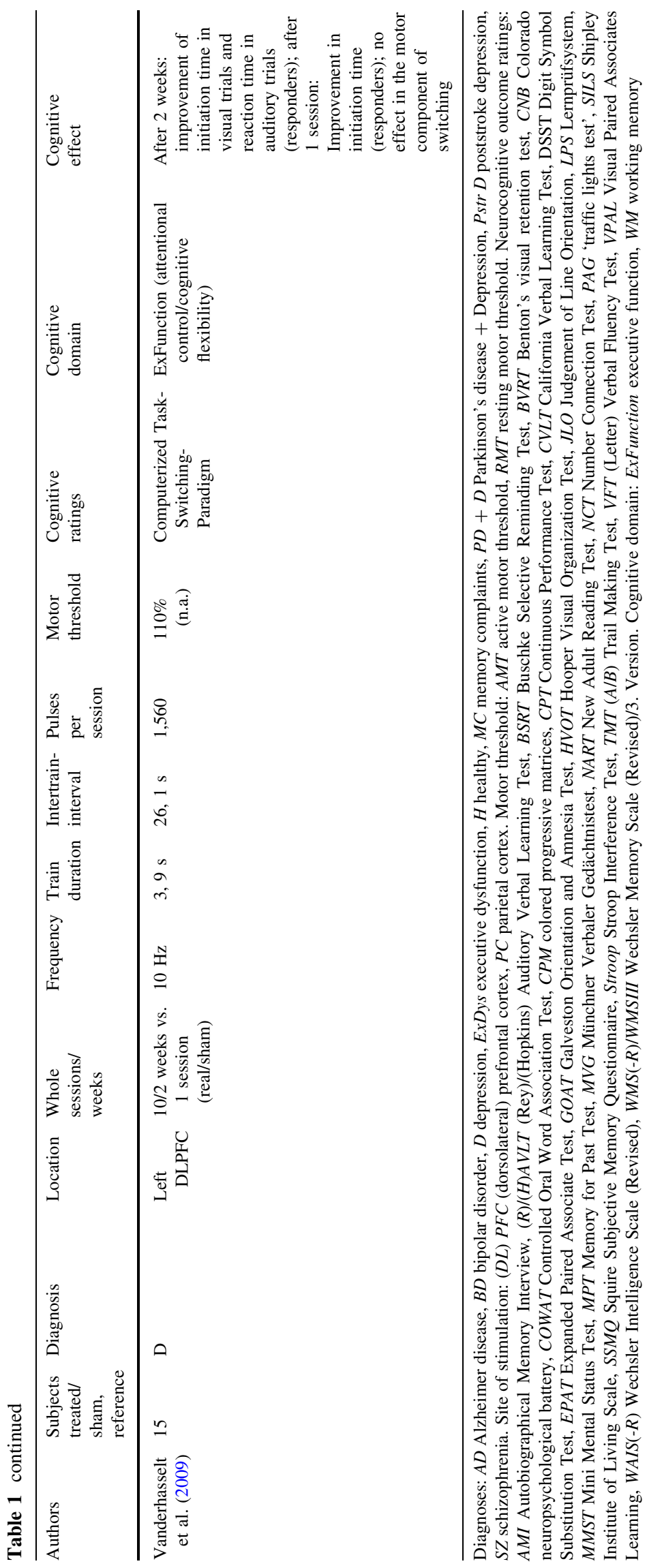


Table 2 Differential cognitive effects of HF rTMS

\begin{tabular}{|c|c|c|c|}
\hline Cognitive domain & Improvement & No effect (n. s.) & Deterioration \\
\hline \multicolumn{4}{|l|}{ Attention } \\
\hline Alertness/Simple reaction & & $\begin{array}{l}3 \text { (Padberg et al. 1999; Loo 2001; Shajahan et al. } \\
\text { 2002) }\end{array}$ & \\
\hline $\begin{array}{l}\text { Selective/Focused attention; } \\
\text { Response inhibition }\end{array}$ & $\begin{array}{l}3 \text { (Martis et al. 2003; } \\
\text { Hausmann et al. 2004; } \\
\text { Rektorova et al. 2005) }\end{array}$ & $\begin{array}{l}9 \text { (Speer et al. 2001; Moser et al. 2002; Huang } \\
\text { et al. } 2004(\mathrm{H}) \text {; Jorge et al. 2004; Mosimann } \\
\text { et al. 2004; Boggio et al. 2005; Avery et al. } \\
\text { 2006; Vanderhasselt et al. } 2006 \text { (H); Wagner } \\
\text { et al. } 2006(\mathrm{H}) \text { ) }\end{array}$ & \\
\hline Divided attention & & & $\begin{array}{l}1 \text { (Wagner et al. } 2006 \\
(\mathrm{H}))\end{array}$ \\
\hline $\begin{array}{l}\text { Sustained attention/ } \\
\text { Concentration }\end{array}$ & $\begin{array}{l}2 \text { (Höppner et al. 2003; } \\
\text { Rektorova et al. 2005) }\end{array}$ & 2 (Speer et al. 2001; Mogg et al. 2008) & \\
\hline \multicolumn{4}{|c|}{ Executive functions/Working memory } \\
\hline $\begin{array}{l}\text { Working memory (Short- } \\
\text { term storage/Manipulation/ } \\
\text { Monitoring) }\end{array}$ & $\begin{array}{l}2 \text { (Martis et al. 2003; } \\
\text { O'Connor et al. 2003) }\end{array}$ & $\begin{array}{l}10 \text { (Triggs et al. 1999; Shajahan et al. 2002; } \\
\text { Fabre et al. 2004; Boggio et al. 2005; } \\
\text { Rektorova et al. 2005; Sachdev et al. 2005; } \\
\text { Schulze-Rauschenbach et al. 2005; Avery } \\
\text { et al. 2006; Rosa et al. 2006; Mogg et al. 2008) }\end{array}$ & \\
\hline Cognitive flexibility & $\begin{array}{l}2 \text { (Moser et al. 2002; } \\
\text { Hausmann et al. 2004) }\end{array}$ & $\begin{array}{l}10 \text { (Speer et al. 2001; Fabre et al. 2004; Jorge } \\
\text { et al. 2004; Mosimann et al. 2004; Boggio } \\
\text { et al. 2005; Sachdev et al. 2005; Schulze- } \\
\text { Rauschenbach et al. 2005; Avery et al. 2006; } \\
\text { Kuroda et al. 2006; Wagner et al. } 2006(\mathrm{H}) \text { ) }\end{array}$ & \\
\hline Verbal fluency/Retrieval & $\begin{array}{l}3 \text { (Triggs et al. 1999; Martis } \\
\text { et al. 2003; Fabre et al. 2004) }\end{array}$ & $\begin{array}{l}14 \text { (Little et al. 2000; Loo 2001; Speer et al. } \\
\text { 2001; Moser et al. 2002; Shajahan et al. 2002; } \\
\text { Loo et al. 2003; Hausmann et al. 2004; Jorge } \\
\text { et al. 2004; Mosimann et al. 2004; Boggio } \\
\text { et al. 2005; Rektorova et al. 2005; Sachdev } \\
\text { et al. 2005; Schulze-Rauschenbach et al. 2005; } \\
\text { Avery et al. 2006) }\end{array}$ & \\
\hline $\begin{array}{l}\text { Problem solving/Planning/ } \\
\text { Reasoning }\end{array}$ & & 2 (Loo 2001; Boggio et al. 2005) & 1 (Loo et al. 2003) \\
\hline \multicolumn{4}{|c|}{ Learning + Memory (Intermediate-/Long-term storage) } \\
\hline Verbal learning + Memory & $\begin{array}{l}3 \text { (Padberg et al. 1999; Little } \\
\text { et al. } 2000 \text { (recall); Schulze- } \\
\text { Rauschenbach et al. 2005) }\end{array}$ & $\begin{array}{l}12 \text { (Triggs et al. 1999; Speer et al. 2001; Moser } \\
\text { et al. 2002; Shajahan et al. 2002; Loo et al. } \\
2003 \text { (Learning); O'Connor et al. 2003; Fabre } \\
\text { et al. 2004; Hausmann et al. 2004; Jorge et al. } \\
\text { 2004; Mosimann et al. 2004; Avery et al. } \\
\text { 2006, Rosa et al. 2006) }\end{array}$ & $\begin{array}{l}2 \text { (Loo 2001; Loo et al. } \\
2003 \text { (Retention)) }\end{array}$ \\
\hline $\begin{array}{l}\text { Spatial learning }+ \text { Memory/ } \\
\text { Objective learning }+ \\
\text { Memory }\end{array}$ & 1 (Martis et al. 2003) & $\begin{array}{l}5 \text { (Little et al. 2000; Speer et al. 2001; Fabre } \\
\text { et al. 2004; Jorge et al. 2004, Rosa et al. 2006) }\end{array}$ & \\
\hline $\begin{array}{l}\text { (Visual) Associative learning } \\
+ \text { Memory }\end{array}$ & $\begin{array}{l}2 \text { (Kuroda et al. 2006; Solé- } \\
\text { Padullés et al. 2006) }\end{array}$ & 3 (Loo 2001; Moser et al. 2002; Loo et al. 2003) & \\
\hline $\begin{array}{l}\text { Retrograde/Autobiographic } \\
\text { memory }\end{array}$ & $\begin{array}{l}1 \text { (Schulze-Rauschenbach et al. } \\
2005)\end{array}$ & 2 (Loo 2001; O'Connor et al. 2003) & \\
\hline \multicolumn{4}{|l|}{ Psychomotor speed } \\
\hline $\begin{array}{l}\text { Psychomotor speed/ } \\
\text { Processing speed }\end{array}$ & $\begin{array}{l}4 \text { (Martis et al. 2003; } \\
\text { Hausmann et al. 2004; Huber } \\
\text { et al. } 2003 \text { (females); } \\
\text { Vanderhasselt et al. } 2006 \\
\text { (H)) }\end{array}$ & $\begin{array}{l}13 \text { (Rollnik et al. 2000; Loo 2001; Speer et al. } \\
\text { 2001; Moser et al. 2002; Höppner et al. 2003; } \\
\text { Huber et al. } 2003 \text { (males); Fabre et al. 2004; } \\
\text { Rektorova et al. 2005; Sachdev et al. 2005; } \\
\text { Schulze-Rauschenbach et al. 2005; Avery } \\
\text { et al. 2006; Kuroda et al. 2006; Mogg et al. } \\
\text { 2008) }\end{array}$ & \\
\hline
\end{tabular}

Vanderhasselt et al. 2009 not included; $(H)$ healthy sample 
to find a significant effect in this domain (Mogg et al. 2008; Speer et al. 2001).

Regarding the allocated studies, about 23 assessed executive functions/working memory in patients (21) and/or healthy subjects (2). Significant improvements were found in the domains working memory, cognitive flexibility and verbal fluency/retrieval (Fabre et al. 2004; Hausmann et al. 2004; Little et al. 2000; Martis et al. 2003; Moser et al. 2002; O’Connor et al. 2003; Triggs et al. 1999; Vanderhasselt et al. 2009). Problem solving/reasoning remained without any beneficial but one adverse effect (Boggio et al. 2005; Loo 2001; Loo et al. 2003). In a great amount of studies improvements were slight and failed to reach significance, but a variety of studies report on trends (for more details see, Tables 1, 2).

Concerning the results of the learning and memory section there are 19 studies quantifying this dimension. Little et al. (2000), Padberg et al. (1999) and SchulzeRauschenbach et al. (2005) discovered verbal learning/ memory improvements, but a great range of authors did not find such statistically relevant effects (see, Table 2). Loo (2001) found an individual temporary deterioration in verbal learning/memory, two years later the same group manifested a selective deterioration in the retention of verbal material (Loo et al. 2003). However, ameliorations were reported in spatial and objective learning/ memory (Little et al. 2000; Martis et al. 2003). In other studies subjects did not exhibit any relevant objective memory change (Fabre et al. 2004; Jorge et al. 2004; Speer et al. 2001). Subjects of other studies reached high scores in associative learning/memory (Kuroda et al. 2006; Solé-Padullés et al. 2006) and in autobiographic memory (Schulze-Rauschenbach et al. 2005). Missing effects in the latter categories are described by Loo et al. (2001, 2003), Moser et al. (2002) and O'Connor et al. (2003).

As much as 16 studies explicitly assessed psychomotor speed/processing speed with the Trail-Making-Test (Version A), the d2-Test or the Stroop-Paradigm. Overall, three studies stated improved psychomotor speed in different tasks (Hausmann et al. 2004; Martis et al. 2003; Vanderhasselt et al. 2006), one found gender differences in terms of improvements in women and no improvements in men (Huber et al. 2003), the others did not find relevant effects (for details see, Table 2).

Effect of clinical status and stimulation type on cognitive changes

As mentioned above our review reports the results of 27 clinical studies (involving patients with distinct diseases) and 3 non-clinical studies (including only healthy volunteers). At first, we compare the different groups with regard to the cognitive stimulation effect. We then summarize the stimulation parameters in terms of their relative cognitive effect. Finally, we contrast the stimulation conditions "real (verum)" and "placebo (sham)" to give an overview of placebo- or real rTMS-induced effects.

\section{Clinical versus non-clinical group}

One of the non-clinical groups stimulating over the (left) PFC showed ameliorations in processing speed (Vanderhasselt et al. 2006), whereas the others did not exhibit relevant improving effects (Huang et al. 2004; Wagner et al. 2006). However, Wagner et al. (2006) found an individual deterioration in divided attention (visual reaction time was slowed). Over all non-clinical groups a single amelioration (in processing speed) can be manifested. Regarding the clinical groups, there are 22 reported ameliorations spanning the domains attention (selective, sustained), executive functions (working memory, cognitive flexibility and verbal fluency/retrieval), learning and memory (verbal, nonverbal) and processing speed. Nevertheless, a great number of studies did not find significant effects over these domains (Table 2). Deteriorations are reported in verbal learning/memory (Loo 2001; Loo et al. 2003) and in planning (Loo et al. 2003).

\section{Stimulation parameters}

In the majority of studies (18) subjects had 10 stimulation sessions in 2 weeks (see, Table 1). The frequencies range between $10 \mathrm{~Hz}$ and $20 \mathrm{~Hz}$, the motor threshold between 80 and $100 \%$. There is a notable difference between intertrain intervals ranging from $5 \mathrm{~s}$ over $24-28 \mathrm{~s}$ up to about 60$90 \mathrm{~s}$. In consideration of all positive cognitive outcomes (15), those studies using stimulation frequencies of $10 \mathrm{~Hz}$ up to $20 \mathrm{~Hz}$ over a period of 2 up to 4 weeks (22) seem to be most effective. Two studies which attained significant improving effects with 10-20 Hz assessed five rTMS sessions only (Moser et al. 2002; Triggs et al. 1999), in the two other studies participants received one sham and one real rTMS session (Rektorova et al. 2005; Vanderhasselt et al. 2006). Seven studies with abovementioned stimulation parameters $(10-20 \mathrm{~Hz}, 2-4$ weeks) are lacking significant cognitive improvement, but indicate a trend of cognitive amelioration anyhow (Boggio et al. 2005; Jorge et al. 2004; Loo et al. 2003; Mosimann et al. 2004; Rosa et al. 2006; Speer et al. 2001). Three others do not report on any improving effect at these stimulation conditions (Loo 2001; Mogg et al. 2008; Shajahan et al. 2002). With regard studies using frequencies at the lower end of the high-frequency range $(5 \mathrm{~Hz})$, there were no marked improvements in cognitive functions (Huang et al. 2004; Shajahan et al. 2002), one study found a tendency of 
cognitive ameliorations (Solé-Padullés et al. 2006), but, except for the latter case, the studies are composed of single stimulation sessions.

\section{Onset of cognitive measure}

We looked into the studies to identify the time interval between last rTMS administration and test onset. All studies performed baseline cognitive testing prior or one day before the first rTMS session. Most studies (19) reported on cognitive measures the day of completing all sessions without specifying the exact onset (Avery et al. 2006; Boggio et al. 2005; Hausmann et al. 2004; Höppner et al. 2003; Huber et al. 2003; Jorge et al. 2004; Loo 2001; Loo et al. 2003; Mogg et al. 2008; Moser et al. 2002; Mosimann et al. 2004; O'Connor et al. 2003; Padberg et al. 1999; Rollnik et al. 2000; Rosa et al. 2006; Sachdev et al. 2005; Speer et al. 2001; Triggs et al. 1999; Vanderhasselt et al. 2006). Among these studies 18 used frequencies of $10-20 \mathrm{~Hz}$ over a longer period (10-20 sessions $(n=16), 5$ sessions $(n=2))$, but only 6 of them described significant positive cognitive outcomes being associated with rTMS intervention. The others mainly showed either a trend of cognitive improvement in verum group or did not detect differences between groups (see, Sect. Discussion). Two further studies exhibited temporary deteriorations.

The other studies described adequately the delay between stimulation and test onset ranging from immediate testing (Huang et al. 2004; Rektorova et al. 2005; Shajahan et al. 2002; Solé-Padullés et al. 2006), 10-30 min (Little et al. 2000; Wagner et al. 2006; Vanderhasselt et al. 2009), 20-24 h (Fabre et al. 2004), one or 3 days (Kuroda et al. 2006; Martis et al. 2003) up to one week (Schulze-Rauschenbach et al. 2005). Five studies integrated follow-up measures (Boggio et al. 2005; Höppner et al. 2003; Mogg et al. 2008; O'Connor et al. 2003; Triggs et al. 1999), eight studies intermediate measures (Triggs et al. 1999; Loo 2001; Rollnik et al. 2000; Shajahan et al. 2002; Little et al. 2000; O'Connor et al. 2003; Rosa et al. 2006; Vanderhasselt et al. 2009).

\section{Verum versus sham stimulation}

Overall, 19 studies are sham-controlled, among these studies 7 are designed crossover and "within subject" or "within group". Two of these studies were excluded because of a small sham-sample (Little et al. 2000) or of only a single sham session crossover (Vanderhasselt et al. 2009). For the sham procedure there were 13 studies using active coils angulated at $45^{\circ}$ or $90^{\circ}$ and 4 studies using sham coils. Therefore, we did not perform a comparison of the different sham procedures. In the presentation of results we only considered the main outcome of each analysis. The impact of clinical status and stimulation condition (real vs. sham) is outlined in regard to the relative cognitive effect in Table 3.

Thus, individual (may be opposing) results were not listed separately, but integrated in the overall report. According to the hypothesis, 7 studies confirm a significantly greater improvement of cognition in verum than in sham condition. Another 8 studies do not reveal relevant differences in cognition between stimulation conditions (in terms of no significant improvement in both conditions). The latter studies include trends toward improvements as well as significant improvements in individual domains that are not reported in detail. For that reason a reclassification of some cases into the last category ("overall cognitive improvement", see Table 3) can be argued. There is no greater sham than verum effect, but interestingly, one study implicates a selective advantage in a planning task of sham over verum stimulation (Loo et al. 2003). Two studies report on overall cognitive improvement, i.e. ameliorations in both stimulation conditions (Avery et al. 2006; Solé-Padullés et al. 2006), that could be due to practice or placebo effects.

\section{High-frequency versus low-frequency stimulation}

Low-frequency studies meeting the predefined criteria are outlined in Table 4. To overview their cognitive outcome, low-frequency stimulation $(=1 \mathrm{~Hz})$ seems to deteriorate cognitive functioning in lieu of having improving effects.
Table 3 Comparison sham versus verum stimulation in high-frequency studies: main outcome

\begin{tabular}{ll}
\hline Group specific cognitive effect & Studies contrasting real and placebo stimulation \\
\hline $\begin{array}{l}\text { No significant improvement: Verum }= \\
\text { Sham }\end{array}$ & (Loo 2001; Loo et al. 2003; Hausmann et al. 2004; Huang et al. \\
& 2004; Jorge et al. 2004; Mosimann et al. 2004; Boggio et al. \\
& 2005; Mogg et al. 2008) \\
Selective improvement: Verum $>$ Sham & (Padberg et al. 1999; Rollnik et al. 2000; Speer et al. 2001; \\
& Moser et al. 2002; Höppner et al. 2003; Vanderhasselt et al. \\
& 2006; Wagner et al. 2006) \\
Selective improvement: Sham $>$ Verum & n. a. \\
$\begin{array}{ll}\text { Overall improvement (placebo-/ } \\
\text { practice effect): Verum = Sham }\end{array}$ & 2 (Avery et al. 2006; Solé-Padullés et al. 2006) \\
\hline
\end{tabular}




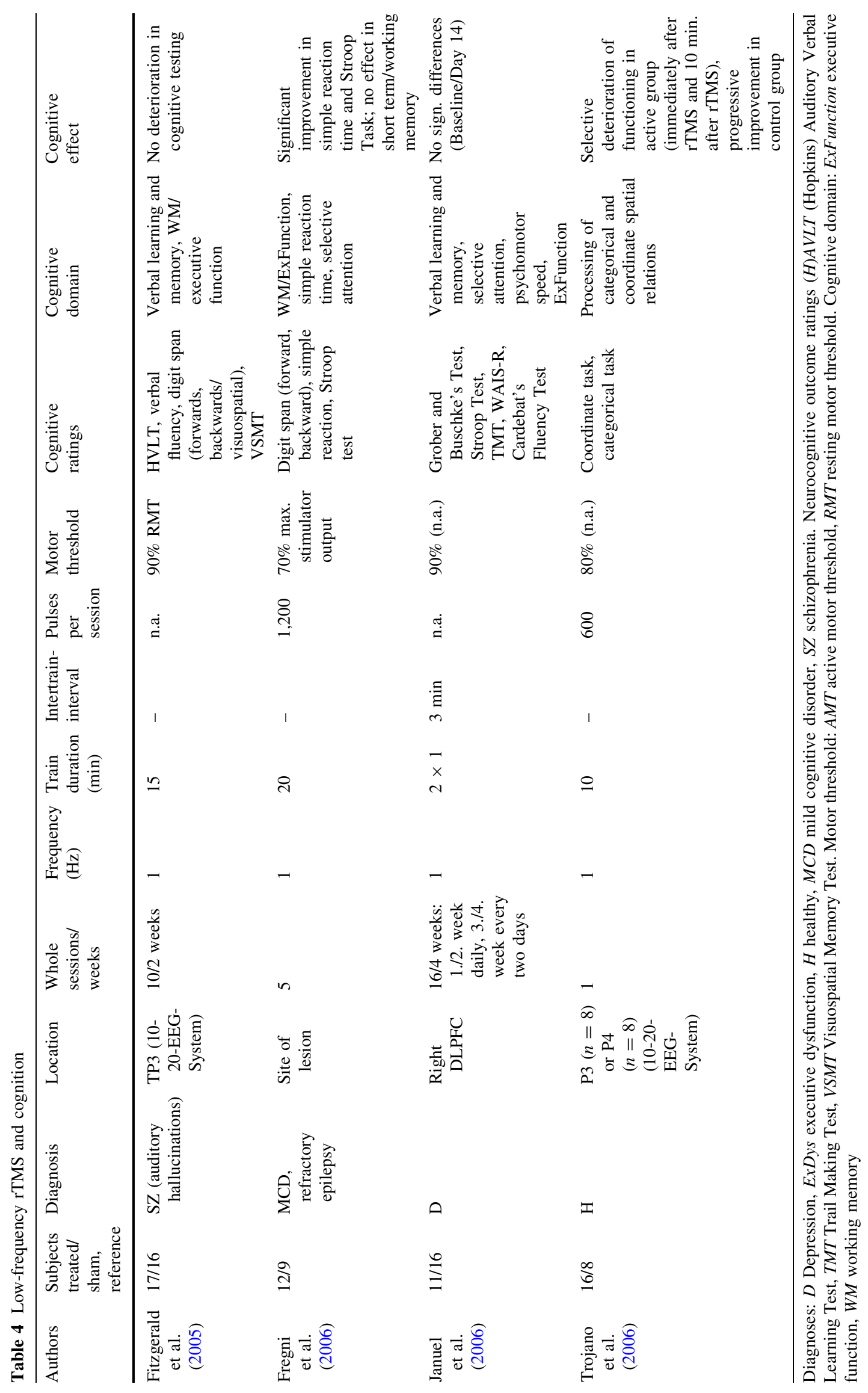


One study described improved simple reaction times and better scores in the Stroop Task, but this had been associated with a reduced seizure activity in epilepsy patients by the authors (Fregni et al. 2006). Two studies report no worsening cognitive effects (Fitzgerald et al. 2005; Januel et al. 2006), and one study by Trojano et al. (2006) referred a selective deterioration of functioning directly and after $10 \mathrm{~min}$ of $1-\mathrm{Hz}$ stimulation.

\section{Discussion}

Overall results and limitations of the studies

To summarize the results, we can state that high-frequency rTMS $(10-20 \mathrm{~Hz})$ is most likely to cause significant cognitive improvement when applied over the left (dorsolateral) prefrontal cortex, within a range of 10-15 successive sessions and an individual motor threshold between 80 and $110 \%$. Regarding the analyses of clinical status and stimulation condition concerning the efficacy of rTMS, the clinical group is superior to the non-clinical group and verum stimulation is in general superior to sham stimulation. All in all, many studies failed to demonstrate significant cognitive effects, but they could show trends toward selective cognitive improvements. In comparison with studies using $1-\mathrm{Hz}$ stimulation, high-frequency studies seem to be superior concerning the cognitive outcome. However, the evaluation is limited due to partly methodological differences between and within studies or to the marginal number of low-frequency studies. General limitations concern the absence of healthy control groups as well as sham conditions to some extent. Important to note is the marginal number of studies using functional imaging and integrating follow-up measures for the exploration of long-term effects. The relative high number of studies giving evidence of placebo or practice effects requires future amendment of control conditions. There are discrepancies concerning the onsets of cognitive testing after rTMS administration being substantially relevant for the outcome. Therefore, results seem to be inconsistent throughout the literature and the particular biological mechanism of rTMS for cognitive improvement seems to be questionable until the underlying pathophysiology remains unclear. We do not know how long the effects of rTMS on cognitive function will persist. Studies investigating systematically the duration of the induced cognitive effects are lacking, but one can assume, based on the remaining effects on psychopathology (e.g. improvement of mood), that also the cognitive improvement will persist for a certain period of time. Future work is needed to systematically investigate the impact of different test onsets after rTMS application.
It should also be further addressed that the correct positioning of the coil is important for the effects of rTMS. Most of the studies used the method of Pascual-Leone (placing the coil $5 \mathrm{~cm}$ rostrally from the hot spot of primary motor cortex) to identify the DLPCF or localized the left DLPFC by the 10-20 EEG-system. While recent studies on neuronavigation for TMS have shown that stereotactically neuronavigated TMS results in stronger and more robust TMS effects, neuronavigation may be important for inducing long-lasting cognitive improvement. For example, one study demonstrated a systematic difference in the behavioral effect size due to the way of localization. Individual fMRI-guided TMS neuronavigation yielded the strongest and the 10-20 EEG-system stimulation approach the smallest behavioral effect size (Sack et al. 2009). There was a nearly tenfold increase in the needed number of probands to induce the same behavioral effect when using the 10-20 system compared to fMRI-guided neuronavigation. In addition, a previous study demonstrated clearly that in most cases the DLPFC was not targeted correctly when compared to the commonly used method of Pascual-Leone with neuronavigated coil positioning (Herwig et al. 2001).

\section{Effects on different cognitive domains}

To discuss the effect of rTMS on attention, one has to consider the different elements that build attentional processes. A basal part of attention is the alertness, which is generally separated in tonic alertness, representing the enduring alert state over the day, and phasic alertness, implying the temporary enhancement of this state due to an internal or external stimulus (Posner 1975). The maintenance of concentration over a longer period of time under monotonous stimulus conditions is called sustained attention (Davies et al. 1984), whereas divided attention is commonly characterized by keeping on line two or more currently relevant (classes of) stimuli or mental operations at the same time. Therefore, divided attention requires the simultaneous monitoring of different information channels to quickly detect relevant events and to execute actions according to the actual demand (Posner and Boies 1971). The essential function of selective or focused attention is the selection of a particular subset of the available stimuli for preferential processing and, consequently, the simultaneous suppression of currently irrelevant information (Kinchla 1992). Important to note is that the concept of divided and selective attention is closely connected to the concept of executive functions. The studies reviewed in our work mainly found improvements in selective and sustained attention, not in alertness. The concept of executive function describes higher cognitive processes like problem solving, mental planning, initiation and inhibition of behavior as well as action control. The main function of the 
executive system is monitoring cognitive (sub-) processes and their flexible dynamic regulation due to changing environments. Such adaptive behavior necessitates a flexible mind, which maintains and updates currently relevant information and exerts top-down control over the perception of incoming information and execution of outgoing behavior. This control is most commonly associated with the anterior pole of the brain, the prefrontal cortex (PFC) (Fuster 1987; Miller and Cohen 2001; Chao and Knight 1995). For successfully using executive control the ability of dynamic attentional shifting is necessary. Working memory consists of the short-term storage of incoming information and a set of executive processes. Short-term storage involves the active maintenance of a limited amount of information for a matter of seconds and is a necessary component of many higher cognitive functions mediated in part by the prefrontal cortex (PFC). The executive component implies the mental manipulation of maintained information (Carpenter et al. 1990; Fuster 1987; Goldmann-Rakic (1997); Stuss and Benson 1986). Therefore, working memory is often operationalized by continuous performance tasks requiring the permanent maintenance and manipulation of incoming information. As executive function and working memory were attributed to prefrontal cortex, one could expect a significant influence of rTMS on these cognitive domains. Nevertheless, the presented studies do not exhibit high significances. They mainly report on improvements in "working memory", "cognitive flexibility" or "verbal fluency", but there are no effects in problem solving, planning or reasoning. Maybe such higher cognitions require too specific modulations of activity than they could be effectively modified by rTMS. We do not know whether executive improvements underlie alterations in basic functions like attention or concentration.

Concerning the learning and memory section, memory refers to intermediate- and long-term storage of information and has to be distinguished from short-term storage or working memory described above. It contains the encoding, consolidation and retention of verbal and nonverbal material. Therefore, tasks used are requiring the immediate and delayed free recall or cued recognition of information. With regard to the well known memory complaints after electroconvulsive therapy (ECT), it is important to note that no marked memory deficits have been found after rTMS. In addition to this outcome beneficial therapeutic (e.g. antidepressant) effects have been the consequence. RTMS (compared to ECT) seems to be a more sensitive technique while exhibiting therapeutic and even improving cognitive effects.

Psychomotor speed/processing speed describes the time a person needs to process incoming stimuli and to adequately react to them or initiate behavior, e. g. connecting numbers as fast as possible in ascending order. Only a few studies indicate significant increase in processing/motor speed when measured solely.

All in all, there are inconsistencies between results that may be attributed to differences in methodology (e.g. stimulation protocols, number of sessions, for details see, Table 1) or sample constitution. Missing statistical power in some cases may be due to marginal psychometric test properties. The evaluation of results is difficult on account of the sometimes overlapping contents of cognitive domains.

What kind of cerebral changes due to rTMS may result in improving behavioral outcomes?

Regarding the differential rTMS effects throughout the literature, evidence is growing about the modification of cerebral blood flow, glucose metabolism and neuronal excitability in the stimulated area as well as in interconnected brain regions (Conca et al. 2002; Fox et al. 1997). Moreover, short-/long-term potentiation of synapses and rapid dynamic alterations in gray matter (GM) density are reported (Esser et al. 2006; May et al. 2007). The latter result resembles structural changes in normal learning mechanisms that could be triggered by high-frequency rTMS pulses. The reported dynamic shift of gray matter density after about 5 days of stimulation is attended by clinical ameliorations within the same time. The occurrence of structural alterations mirrored by changes in functional processing exemplifies structural neuroplasticity as a counterpart of function. Furthermore, there is a large body of literature suggesting an association of hypofrontality in schizophrenia with negative symptoms and cognitive deficits (Dolan et al. 1993; George and Belmaker 2000; Weinberger et al. 1988). High-frequency rTMS (especially at $10 \mathrm{~Hz}$ ) seems to be a promising technique to improve such negative symptoms (Hajak et al. 2004; Cordes et al. 2005; Jin et al. 2006). Consequently, high-frequency rTMS can be suggested to be able to evoke improvements in both negative symptoms and cognition. The herein reviewed rTMS studies assessing cognition in schizophrenia did not show convincing effects toward a cognitive improvement. Additionally, it remains unclear whether structural changes, alterations in metabolism or neurotransmission under the stimulated area or in the connected neuronal network (or the combination of all) may produce behavioral outcomes (e.g. May et al. 2007; Strafella et al. 2001). Regarding the stimulation location (PFC) one could expect improvements in most of the abovementioned cognitive functions, because they all underlie (at least in part) this area. Nevertheless, the results of the studies do not exhibit such consistent pattern. 
The mechanism how rTMS may lead to an improvement of cognitive function is rather complex and raises some difficulties in interpretation. TMS-induced enhancement of performance might be the result of the excitation of a functionally relevant task-supporting activation, the excitation of an area that inhibits competing functions, the inhibition of an area that suppresses the execution of the task, or the inhibition of an area that promotes competing functions (Sack and Linden 2003). This is complicated by the fact that the same stimulation pattern (e.g. suprathreshold rTMS with $10 \mathrm{~Hz}$ ) could lead to different effects on cerebral blood flow depending on the stimulation site (e.g. increase when stimulating the frontal eye field and decrease during rTMS of the primary motor cortex) (Sack and Linden 2003). The effects of rTMS also depend on the history of synaptic activity in the stimulated region. For example, if 6-Hz rTMS is applied for a short period (below the threshold for any lasting after-effects), then the suppressive effect of a subsequent period of $1-\mathrm{Hz}$ rTMS is enhanced (Ridding and Rothwell 2007). Generally, a prior history of increased activity seems to increase the effectiveness of rTMS protocols that decrease excitability, whereas a prior history of reduced activity increases the effect of facilitatory rTMS.

Further differential investigations are necessary to expand knowledge of rTMS functioning and the underlying biological mechanisms by linking structural and functional imaging data (including spectroscopy data) with behavioral outcome variables. For a detailed analysis of functional cerebral alterations, the rTMS procedure could be conducted during fMRI-scanning. Such a simultaneous approach provides the opportunity to investigate the local response to TMS at a neurophysiological level with high spatial resolution, thus helping to determine in vivo the brain areas that are directly or transsynaptically affected by TMS. Nevertheless using fMRI tends to create also problems with interpretation; for example, whether changes in perfusion or BOLD signal reflect changes in excitatory, inhibitory or combined neural activity.

An interesting topic in this context could also be to evaluate and compare the contrast of brain alterations and differences in activated neuronal networks in diseased and healthy people to explore different coping strategies. All in all, investigations have to prove the efficacy of rTMS in randomized sham-controlled trials with higher statistical power using larger sample sizes and improved methodology. This may even become more interesting while stimulation protocols inducing longer-lasting effects like theta-burst stimulation (TBS) have been developed. Currently studies are underway to test these TBS in terms of affecting not only motor response, but also cognition.
Acknowledgments T. Wobrock is a member of a speakers' bureau for AstraZeneca, Eli Lilly and Janssen-Cilag, and has accepted paid speaking engagements in industry-sponsored symposia from AstraZeneca, Bristol-Myers-Squibb, Eli-Lilly, Janssen Cilag and Pfizer, and travel or hospitality not related to a speaking engagement from Astra Zeneca, Bristol-Myers-Squibb, Eli Lilly, Janssen Cilag, and Sanofi-Synthelabo, and received a research grant from Astra Zeneca. B. Guse reports no competing interests.

\section{References}

Avery DH, Hotzheimer PE, Fawaz W, Russo J, Neumaier J, Dunner DL, Haynor DR, Claypoole KH, Wajdik C, Roy-Byrne P (2006) A controlled study of repetitive transcranial magnetic stimulation in medication-resistant major depression. Biol Psychiatry 59:187-194

Barker AT, Jalinous R, Freeston IL (1985) Non-invasive magnetic stimulation of human motor cortex (letter). Lancet 1:1106-1107

Ben-Shachar D, Belmaker RH, Grisaru N, Klein E (1997) Transcranial magnetic stimulation induces alternations in brain monoamines. J Neural Transm 104:191-197

Boggio PS, Fregni F, Bermpohl F, Mansur CG, Rosa M, Rumi DO, Barbosa ER, Rosa MO, Pascual-Leone A, Rigonatti SP, Marcolin MA, Silva MTA (2005) Effect of repetitive TMS and fluoxetine on cognitive function in patients with Parkinson's disease and concurrent depression. Brief reports. Mov Disord 20(9):1178-1219

Burt T, Lisanby SH, Sackheim HA (2002) Neuropsychiatric applications of transcranial magnetic stimulation: a meta analysis. Int J Neuropsychopharmacol 5:73-103

Carpenter PA, Just MA, Shell P (1990) What one intelligence test measures: a theoretical account of the processing in the Raven Progressive Matrices Test. Psychol Rev 97:404-431

Chao LL, Knight RT (1995) Human prefrontal lesions increase distractibility to irrelevant sensory inputs. Neuroreport 21:16051610

Conca A, Koppi S, Konig P, Swoboda E, Krecke N (1996) Transcranial magnetic stimulation: a novel antidepressive strategy? Neuropsychobiology 34:204-207

Conca A, Peschina W, Konig P, Fritzsche H, Hausmann A (2002) Effect of chronic repetitive transcranial magnetic stimulation on regional cerebral blood flow and regional glucose uptake in drug treatment-resistant depressives: a brief report. Neuropsychobiology 45:27-31

Cordes J, Mobascher A, Arends M, Agelink MW, Klimke A (2005) A new method for the treatment of depression: Transcranial magnetic stimulation. Dtsch Med Wochenschr 130:889-892

Davies DR, Jones DM, Taylor A (1984) Selective and sustainedattention tasks: Individual and group differences. In: Parasuraman R, Davies DR (eds) Varieties of Attention. Academic, Orlando

Dolan RJ, Bench CJ, Liddle PF (1993) Dorsolateral prefrontal cortex dysfunction in the major psychoses: symptoms or disease specificity? J Neurosurg Psychiatr 56:1290-1294

Esser SK, Huber R, Massimini M, Peterson MJ, Ferrarelli F, Tononi G (2006) A direct demonstration of cortical LTP in humans: A combined TMS/EEG study. J Brain Res Bull 69(1):86-94

Fabre I, Galinowski A, Oppenheim C, Gallarda T, Meder JF, de Montigny C, Olié JP, Poirier MF (2004) Antidepressant efficacy and cognitive effects of repetitive transcranial magnetic stimulation in vascular depression: an open trial. Int $\mathrm{J}$ Geriatr Psychiatry 19:833-842

Fitzgerald PB, Benitez J, Daskalakis JZ, Brown TL, Marston N, de Castella A, Kulkarni J (2005) A double-blind sham-controlled 
trial of repetitive transcranial magnetic stimulation in the treatment of refractory auditory hallucinations. J Clin Psychopharmacol 25(4):358-362

Fox P, Ingham R, George MS, Mayberg H, Ingham J, Roby J, Martin C, Jerabek P (1997) Imaging human intra-cerebral connectivity ba PET during rTMS. Neuroreport 8:2787-2791

Fregni F, Otachi P, do Valle A, Boggio PS, Thut G, Rigonatti S, Pascual-Leone A, Valente KD (2006) A randomized clinical trial of repetitive transcranial magnetic stimulation in patients with refractory epilepsy. Ann Neurol 60:447-455

Fuster JM (1987) The prefrontal cortex: anatomy, physiology, and neuropsychology of the frontal lobe. Lippincott-Raven, New York

George MS, Belmaker RH (2000) Transcranial magnetic stimulation in neuropsychiatry. American Psychiatric Association, Washington

Gershon AA, Dannon PN, Grunhaus L (2003) Transcranial magnetic stimulation in the treatment of depression. Am J Psychiatry 160:835-845

Goldmann-Rakic PS (1997) Circuitry of primate prefrontal cortex and regulation of behaviour by representational memory. In: Plum F (ed) Handbook of physiology. Nervous system, vol 5. Higher functions of the brain. American Physiological Society, Bethesda, pp 373-417

Hajak G, Marienhagen J, Langguth B, Werner S, Binder H, Eichhammer P (2004) High frequency transcranial magnetic stimulation in schizophrenia: a combined treatment and neuroimaging study. Psychol Med 34:1157-1163

Haraldsson HM, Ferrarelli F, Kalin NH, Tononi G (2004) Transcranial magnetic stimulation in the investigation and treatment of schizophrenia: a review. Schizophr Res 71:1-16

Hausmann A, Pascual-Leone A, Kemmler G, Rupp CI, LechnerSchoner T, Kramer-Reinstadler K, Walpoth M, Mechtcheriakov S, Conca A, Weiss EM (2004) No deterioration of cognitive performance in an aggressive unilateral and bilateral antidepressant rTMS add-on trial. J Clin Psychiatry 65(6):772-782

Herwig U, Padberg F, Unger J, Spitzer M, Schönfeldt-Lecuona C (2001) Transcranial magnetic stimulation in therapy studies: examination of the reliability of "standard" coil positioning by neuronavigation. Biol Psychiatry 50(1):58-61

Hoffmann RE, Gueorguieva R, Hawkins KA, Varanko M, Boutros NN, Wu YT, Caroll K, Krystal JH (2005) Temporoparietal transcranial magnetic stimulation for auditory hallucinations: safety, efficacy and moderators in a fifty patients sample. Biol Psychiatry 58:97-104

Höppner J, Schulz M, Mau R, Schläfke D, Richter J (2003) Antidepressant efficacy of two different rTMS procedures. Eur Arch Psychiatry Clin Neurosci 253:103-109

Huang CC, Su TP, Shan IK, Wei IH (2004) Effect of $5 \mathrm{~Hz}$ repetitive transcranial magnetic stimulation on cognition during a $\mathrm{Go} /$ NoGo task. J Psychiatr Res 38:513-520

Huber TJ, Schneider U, Rollnik J (2003) Gender differences in the effect of repetitive transcranial magnetic stimulation in schizophrenia. Psychiatry Res 120(1):103-105

Jandl M, Bittner R, Sack A, Weber B, Günther T, Maurer K, Kaschka WP (2004) Effects of rTMS on negative symptoms and EEGtopography in schizophrenic patients. Eur Psychiatry 19(Suppl 1): 164

Jandl M, Bittner R, Sack A, Weber B, Günther T, Pieschl D, Kaschka WP, Maurer K (2005) Changes in negative symptoms and EEG in schizophrenic patients after repetitive transcranial magnetic stimulation (rTMS): an open-label pilot study. J Neural Transm 112:955-967

Januel D, Dumortier G, Verdon CM, Stamatiadis L, Saba G, Cabaret W, Benadhira R, Rocamora JF, Braha S, Kalalou K, Vicaut PE, Fermanian J (2006) A double-blind sham controlled study of right prefrontal repetitive transcranial magnetic stimulation (rTMS): Therapeutic and cognitive effect in medication free unipolar depression during 4 weeks. Prog Neuropsychopharmacol Biol Psychiatry 30(1):126-130

Jin Y, Potkin SG, Kemp AS, Huerta ST, Alva G, Thai TM, Carreon D, Bunney WE Jr (2006) Therapeutic effects of individualized alpha frequency transcranial magnetic stimulation (alpha rTMS) on negative symptoms of schizophrenia. Schizophr Bull 32:556-561

Jorge RE, Robinson RG, Tateno A, Narushima K, Acion L, Moser L, Arndt S, Chemerinski E (2004) Repetitive transcranial magnetic stimulation as treatment of poststroke depression: a preliminary study. Biol Psychiatry 55:398-405

Kinchla RA (1992) Attention. Annu Rev Psychol 43:711-742

Kuroda Y, Motohashi N, Ito H, Ito S, Takano A, Nishikawa T, Suhara $\mathrm{T}$ (2006) Effects of repetitive transcranial magnetic stimulation on $\left[{ }^{11} \mathrm{C}\right]$ raclopride binding and cognitive function in patients with depression. J Affect Disord 95:35-42

Little JT, Kimbrell TA, Wassermann EM, Grafman J, Figueras S, Dunn RT, Danielson A, Repella J, Huggins T, George MS, Post RM (2000) Cognitive effects of 1- and 20-Hertz repetitive transcranial magnetic stimulation in depression: preliminary report. Neuropsychiatry Neuropsychol Behav Neurol 13(2): $119-124$

Loo C (2001) Effects of a 2- to 4-week course of repetitive transcranial magnetic stimulation (rTMS) on neuropsychologic functioning, electroencephalogram, and auditory threshold in depressed patients. Biol Psychiatry 49:615-623

Loo C, Mitchell PB, Croker VM, Malhi GS, Wen W, Gandevia SC, Sachdev PS (2003) Double-blind controlled investigation of bilateral prefrontal transcranial magnetic stimulation for the treatment of resistant major depression. Psychol Med 33:33-40

Martis B, Alam D, Dowd SM, Hill SK, Sharma RP, Rosen C, Pliskin N, Martin E, Carson V, Janicak PG (2003) Neurocognitive effects of repetitive transcranial magnetic stimulation in severe major depression. Clin Neurophysiol 114:1125-1132

May A, Hajak G, Gänsbauer S, Steffens T, Langguth B, Kleinjung T, Eichhammer P (2007) Structural brain alterations following 5 days of intervention: dynamic aspects of neuroplasticity. Cereb Cortex 17:205-210

Miller EK, Cohen JD (2001) An integrative theory of prefrontal cortex function. A Rev Neurosci 24:167-202

Mogg A, Pluck G, Eranti SV, Landau S, Purvis R, Brown RG, Curtis V, Howard R, Philpot M, McLoughlin DM (2008) A randomized controlled trial with 4-month follow-up of adjunctive repetitive transcranial magnetic stimulation of the left prefrontal cortex for depression. Psychol Med 38(3):323-333

Moser DJ, Jorge RE, Manes MD, Paradiso S, Benjamin BS, Robinson RG (2002) Improved executive functioning following repetitive transcranial magnetic stimulation. Neurology 58:1288-1290

Mosimann UP, Schmitt W, Greenberg BD, Kosel M, Müri RM, Berkhoff M, Hess CW, Fisch HU, Schlaepfer TE (2004) Repetitive transcranial magnetic stimulation: a putative add on treatment for major depression in elderly patients. Psychiatr Res 126:123-133

O'Connor M, Brenninkmeyer C, Morgan A, Bloomingdale K, Thall M, Vasile R, Pascual Leone A (2003) Magnetic stimulation and electroconvulsive therapy on mood and memory: a neurocognitive risk-benefit-analysis. Cogn Behav Neurol 6(2):118-127

Padberg F, Zwanzger P, Thoma H, Kathmann N, Haag C, Greenberg BD, Hampel H, Möller HJ (1999) Repetitive transcranial magnetic stimulation (rTMS) in pharmacotherapy-refractory major depression: comparative study of fast, slow and sham rTMS. Psychiatry Res 88(3):163-171

Posner MI (1975) The psychology of attention. In: Gazzaniga MS, Blakemore C (eds) Handbook of psychology. Academic, New York 
Posner MI, Boies SW (1971) Components of attention. Psychol Rev 78:391-408

Post A, Keck ME (2001) Transcranial magnetic stimulation as a therapeutic tool in psychiatry: what do we know about the neurobiological mechanism? J Psychiatr Res 35:193-215

Poulet E, Brunelin J, Bediou B, Forgeard L, Daleru J, D'Amato T, Saoud M (2005) Slow transcranial magnetic stimulation can rapidly reduce resistant auditory hallucinations in schizophrenia. Biol Psychiatry 57:188-191

Rektorova I, Megova S, Bares M, Rektor I (2005) Cognitive functioning after repetitive transcranial magnetic stimulation in patients with cerebrovascular disease without dementia: a pilot study of seven patients. J Neurol Sci 229-230:157-161

Ridding MC, Rothwell JC (2007) Is there a future for therapeutic use of transcranial magnetic stimulation? NatRevNeurosci 8(7): $559-567$

Rollnik JD, Huber TJ, Mogk H, Siggelkow S, Kropp S, Dengler R, Emrich HM, Schneider U (2000) High frequency repetitive transcranial magnetic stimulation (rTMS) of the dorsolateral prefrontal cortex in schizophrenic patients. NeuroReport 11: 4013-4015

Rosa MA, Gattaz WF, Pascual-Leone A, Fregni F, Rosa MO, Rumi DO, Myczkowski M, Silva MF, Mansur C, Rigonatti SP, Teixeira MJ, Marcolin MA (2006) Comparison of repetitive transcranial magnetic stimulation and electroconvulsive therapy in unipolar non-psychotic depression: a randomized single-blind study. Int J Neuropsychopharmacol 9(6):667-676

Sachdev P, Loo C, Mitchell P, Malhi G (2005) Transcranial magnetic stimulation for the deficit syndrome of schizophrenia: A pilot investigation. Psychiatry Clin Neurosci 59(3):354-357

Sack AT, Linden DE (2003) Combining transcranial magnetic stimulation and functional imaging in cognitive brain research: possibilities and limitations. Brain Res Brain Res Rev 43(1): $41-56$

Sack AT, Cohen Kadosh R, Schumann T, Moerel M, Walsh V, Goebel R (2009) Optimizing functional accuracy of TMS in cognitive studies: a comparison of methods. J Cogn Neurosci 21(2):207-221

Sackeim HA, Portnoy S, Neeley P, Steif BL, Decina P, Malitz S (1986) Cognitive consequences of low-dosage electroconvulsive therapy. Ann NY Acad Sci 462:326-340

Schulze-Rauschenbach SC, Harms U, Schlaepfer TE, Maier W, Falkai F, Wagner M (2005) Distinctive neurocognitive effects of repetitive transcranial magnetic stimulation and electroconvulsive therapy in major depression. Br J Psychiatry 186:410-416

Shajahan PM, Glabus MF, Steele JD, Doris AB, Anderson K, Jenkins JA, Gooding PA, Ebmeier KP (2002) Left dorso-lateral repetitive transcranial magnetic stimulation affects cortical excitability and functional connectivity, but does not impair cognition in major depression. Prog Neuropsychopharmacol Biol Psychiatry 26(5):945-954

Solé-Padullés C, Bartrés-Faz D, Junqué C, Clemente IC, Molinuevo JL, Bargalló N, Sánchez-Aldeguer J, Bosch B, Falcón C, VallsSolé J (2006) Repetitive transcranial magnetic stimulation effects on brain function and cognition among elders with memory dysfunction. A randomized sham-controlled study. Cereb Cortex 16:1487-1493

Speer AM, Repella JD, Figueras S, Demian NK, Kimbrell TA, Wasserman EM, Post RM (2001) Lack of adverse cognitive effects of $1 \mathrm{~Hz}$ and $20 \mathrm{~Hz}$ repetitive transcranial magnetic stimulation at $100 \%$ of motor threshold over left prefrontal cortex in depression. J ECT 17(4):259-263

Squire LR (1982) Memory and electroconvulsive therapy (Letter). Am J Psychiatry 139:1221

Strafella A, Paus T, Barrett J, Dagher A (2001) Repetitive transcranial magnetic stimulation of the human prefrontal cortex induces dopamine release in the caudate nucleus. J Neurosci 21(157):1-4

Stuss DT, Benson DF (1986) The frontal lobes. Raven, New York

Triggs WJ, McCoy KJM, Greer R, Rossi F, Bowers D, Kortenkamp S, Nadeau SE, Heilman KM, Goodman WK (1999) Effects of left frontal transcranial magnetic stimulation on depressed mood, cognition, and corticomotor threshold. Biol Psychiatry 45(11): $1440-1446$

Trojano L, Conson M, Maffei R, Grossi D (2006) Categorial and coordinate spatial processing in the imagery domain investigated by rTMS. Neuropsychologia 44(9):1569-1574

Vanderhasselt MA, De Raedt R, Baeken C, Leyman L, D'haenen H (2006) The influence of rTMS over the left dorsolateral prefrontal cortex on Stroop task performance. Exp Brain Res 169:279-282

Vanderhasselt MA, De Raedt R, Leyman L, Baeken C (2009) Acute effects of repetitive transcranial magnetic stimulation on attentional control are related to antidepressant outcomes. J Psychiatry Neurosci 34(2):119-126

Wagner W, Rihs TA, Mosimann UP, Fisch HU, Schlaepfer TE (2006) Repetitive transcranial magnetic stimulation of the dorsolateral prefrontal cortex affects divided attention immediately after cessation of stimulation. J Psychiatr Res 40:315-321

Weinberger DR, Berman KF, Chase TN (1988) Mesocortical dopaminergic function and human cognition. Ann NY Acad Sci 537:330-338

Weiner RD, Rogers HJ, Davidson JR, Squire LR (1986) Effects of stimulus parameters on cognitive side effects. Ann NY Acad Sci 462:315-325

Zimmermann P, Fimm B (1997) Test for Attentional Performance (TAP), version 1.5. Psytest Press, Freiburg 